\title{
Optical behaviour of tetracyanoplatinate (MCP) encapsulated sol-gel glasses
}

\author{
B MAJUMDAR* and MRUNALINI MAHAJAN \\ Department of Physics, Government Model College of Science, Raipur 492 010, India \\ MS received 22 January 1996
}

\begin{abstract}
The photoluminescence spectra at atmospheric pressure and high pressure photoluminescence spectra of the tetracyanoplatinate salts (MCP) KLiCP. $2 \mathrm{H}_{2} \mathrm{O}, \mathrm{KNaCP} \cdot 3 \mathrm{H}_{2} \mathrm{O}$, $\mathrm{Cs}_{2} \mathrm{Ca}(\mathrm{CP})_{2} \cdot n \mathrm{H}_{2} \mathrm{O}$ and $\mathrm{Cs}_{2} \mathrm{CP} \cdot \mathrm{H}_{2} \mathrm{O}$ encapsulated sol-gel glasses are reported. In all these sol-gel glass systems we have found large pressure dependent shift of the photoluminescence maxima under hydrostatic high pressure condition (up to $13 \mathrm{~nm} / \mathrm{kbar}$ ) and therefore, prove to be as most sensitive probes to enable us to calculate pressure at different stages of gelation, aging and drying of the gel glass. The pressure dependent shift, along with the position of the peak maxima and band width at half height, are measured for the photoluminescence spectra at atmospheric pressure as well as at high pressure. Concentration effect has also been studied in the present system to arrive at more conclusive picture of the dopant matrix and dopant-dopant interaction. The fluorescence life time, as well as integrated emission intensity as a function of concentration, have also been studied in all the four glass systems which allows us to identify the dimer and cluster spectra.
\end{abstract}

Keywords. Photoluminescence; high pressure photoluminescence; tetracyanoplatinate; sol-gel.

\section{Introduction}

In recent years sol-gel process has become an attractive and most extensive research area for the preparation of highly homogeneous glasses, ceramics and composites at temperatures lower than the melting temperatures required in the conventional fusing techniques. In addition, the sol-gel route to prepare glass offers considerable advantages, such as, control of composition, low processing temperature, organic modifications of inorganic polymers leading to a new class of glass like materials. The processing of sols to coatings or powders, the possibilities to structurize glasses for chemical sensors, optoelectronic glasses etc are really very fascinating. Recently sol-gel technique has been used for coating of opto-electronic devices and, display along with multilayer wavelength selective reflecting coatings as well as electrochromic coatings have also been carried out (Roy 1987; Mukharjee 1980; Gesser and Goswami 1989; Scherer 1990; Ro and Chung 1989; Kundu et al 1989). Prasad (1989) and Knobbe et al (1989) have recently reported sol-gel derived materials as suitable hosts for organic molecule with a very high response to non-linear optical property. As a matter of fact sol-gel process has, therefore, generated tremendous interest among the research workers who are working in the field of applied chemistry and materials science.

Looking at the wider range of applications of sol-gel technique, we have focussed our attention to synthesize new materials, which in turn would be able to look into the microscopic details of the sol-gel glasses. Our goal in the present research programme is essentially to calculate pressure which develops during drying of the gel whose understanding and control are of extreme importance as far as the preparation of monolithic gels are concerned. We believe that the use of luminescence probe will offer 
us an opportunity to look in depth at the details of the drying process. In carrying out such an experiment, our main focus was to select a very specific spectroscopic probe molecule which would exhibit large change in spectrum as a function of pressure (Scherer 1986, 1987a, b, 1988, 1989; Majumdar and Mahajan 1996a).

The specific probe molecules selected to carry out the above experiment-the tetracyanoplatinate compounds - are considered as most suitable because of their electronic structure and spectroscopic properties of square planar tetracyanide anions. In pure single crystals, these square planar tetracyanide anions exist as their polymer chains with metal bonding along the chain axis (Moreau-Colin 1972; Maffly et al 1977). The different polymer chains are separated by the cations and the water molecules, however, the distance between adjacent metal ions in the same chain is much shorter than the distance between two metal ions from adjacent chains. In the solid state $\operatorname{Pt}(\mathrm{CN})_{4}^{-2}$, chains exhibit a variety of colours while aqueous solutions are colourless, which suggest that during solid state the colour is dependent upon metal-metal bond distance (Viswanath et al 1981).

The TCP compounds have three unique advantages for the proposed studies: First, they are intensely luminescent at room temperature as well as at low temperature. Secondly, they are soluble in alcohols, which are used to make the gels and are known to readily form microcrystals in polar media (Viswanath et al 1981). Thirdly, they exhibit large pressure dependence shift of the optical emission maxima (Stock and Yersin 1976; Yersin et al 1979).

The experimental determination of the pressure that exists during drying at various stages should be carefully verified in order to discriminate between electron impact excitation vs electron hole pair recombination. Thus, the local pressure can be calculated quantitatively using pressure sensitive luminescent probe to determine the pressure in the liquid phase at the exterior surface $\left(P_{E}\right)$. As the evaporation occurs the pressure in the liquid rises to the level required to compress the solid. The maximum to which the pressure can rise is $\left(P_{\mathrm{R}}\right)$, the redistribution pressure which is related to the solid/vapour and solid/liquid interfacial energies $\left(\gamma_{\mathrm{SV}}\right.$ and $\left.\gamma_{\mathrm{SL}}\right)$ as

$$
P_{\mathrm{R}}=\frac{\left(\gamma_{\mathrm{SV}}-\gamma_{\mathrm{SL}}\right) S_{\mathrm{P}}}{V_{\mathrm{P}}}
$$

where $S_{\mathrm{P}}$ and $V_{\mathrm{P}}$ are the surface area and volume of the solvent field pores (Scherer 1987, 1988; Majumdar and Mahajan 1996b).

In most cases, we have found that pressure has significantly lower value inside the gel compared to that at the surface. The magnitude of $P_{\mathrm{R}}$ and the pressure gradient is of direct importance to the issue of cracking during the process of drying. We believe that by characterizing the luminescence from molecular probes at the gel surface, we would be able to obtain information regarding the increase of pressure in gels and in turn build up drying stress as evaporation occurs (Holzapfel et al 1981; Leyrer et al 1985).

An ideal probe which can calculate pressure $P_{\mathrm{R}}$ inside the gel would be provided by a substance that has a large pressure dependent shift of its luminescence maxima. The position of the maxima could be measured as a function of carefully controlled hydrostatic high pressure. The position of the maximum in the emission spectrum recorded during sol to gel and gel to glass transformation could then be compared to that in the photoluminescence spectrum at the known pressure and the pressure gradient during gelation, aging and drying stresses could be calculated. 
We report here for the first time the photoluminescence spectra at $1 \mathrm{~atm}$ as well as high pressure photoluminescence spectra of different species of TCP compounds such as $\mathrm{KNaCP}, \mathrm{KLiCP}, \mathrm{Cs}_{2} \mathrm{Ca}(\mathrm{CP})_{2}, \mathrm{Cs}, \mathrm{CP}$, encapsulated in silicate glass matrix. These TCP compounds have the tendency to crystallize in quasi-one dimensional structure (1-D) where the square planar $\left[\mathrm{Pt}(\mathrm{CN})_{4}\right]^{-2}$ units are stacked in columns (Krogmann 1969; Holzapfel et al 1981; Schultz et al 1982). It is known that the intra-columnar $\mathrm{Pt}-\mathrm{Pt}$ distance is short compared to the separation from column to column which in turn actually results in strongly anisotropic interaction between the complex ions (Yersin and Gliemann 1978; Hidvegi et al 1982; von Ammon and Gliemann 1982).

We have also recorded the emission spectra of $\mathrm{Cs}_{2} \mathrm{CP}$ at $1 \mathrm{~atm}$ under identical optical and geometrical conditions at different stages of gel to glass transformation which are gelation, aging and drying. On the basis of these measurements we would be able to quantify the increase in pressure at the surface as a function of drying time which in turn would be correlated with the gel shrinkage and evaporation. This will enable us to measure the pressure gradient as a function of gel shrinkage at which pressure reaches $P_{\mathbf{R}}$ as well as the mechanistic consequences of the results obtained diring gelation to drying stages.

\section{Experimental}

\subsection{Sample preparation}

The samples of $\mathrm{KLiCP}, \mathrm{Cs}_{2} \mathrm{CP}, \mathrm{KNaCP}$ and $\mathrm{Cs}_{2} \mathrm{Ca}(\mathrm{CP})_{2}$ were grown in the laboratory following literature method (Holzapfel 1978). Few samples of $\mathrm{Cs}_{2} \mathrm{CP}$ and $\mathrm{KNaCP}$ were also prepared in the laboratory following the literature method given by Yersin et al (1979). The samples of $\mathrm{KNaCP}$ were prepared by mixing equimolar amounts of $\mathrm{K}_{2} \mathrm{CP}$ and $\mathrm{Na}_{2} \mathrm{CP}$ in water and slowly reducing the volume of the mixture in a water bath and collecting the yellow crystals. The microcrystals of KNaCP, KLiCP and $\mathrm{Cs}_{2} \mathrm{CP}$ were dissolved in ethanol. We have used tetraethoxysilane as the starting material for silica gel glass formation. Samples of MCP doped tetracyanoplatinate silica gels were made by a modification of the sonogel method described by Esquivias and Zarzycki (1988). A 1:4 ratio of TEOS to a solution of MCP of varying concentrations ranging from $1 \times 10^{-2}$ to $1 \times 10^{-5} \mathrm{M}$ in ethanol (Aldrich) was utilized. $22 \mathrm{ml}$ of sol were taken and the process of hydrolysis was catalysed using five drops of $4 \mathrm{~N} \mathrm{HCl}$. Upon completion of the hydrolysis, the $\mathrm{pH}$ of the sol was adjusted to 4.5 . The sample was then cast into polystyrene cuvettes, covered and allowed to gel. Following gelation, the covers were perforated to allow slow evaporation of residual solvent. Dried xero gels were obtained within approximately six weeks. Probe doped gel specimen were subsequently used for studying the optical behaviour and characterization. The resultant solid matrix is stiff, transparent and light orange coloured non crystalline material with smooth surfaces.

\subsection{Instrumentation}

2.2a Atmospheric pressure photoluminescence spectroscopy: The one-atmosphere photoluminescence spectra were obtained using a Perkin-Elmer MPF 44A fluorescence spectrophotometer equipped with a spectral correction unit and a low temperature 


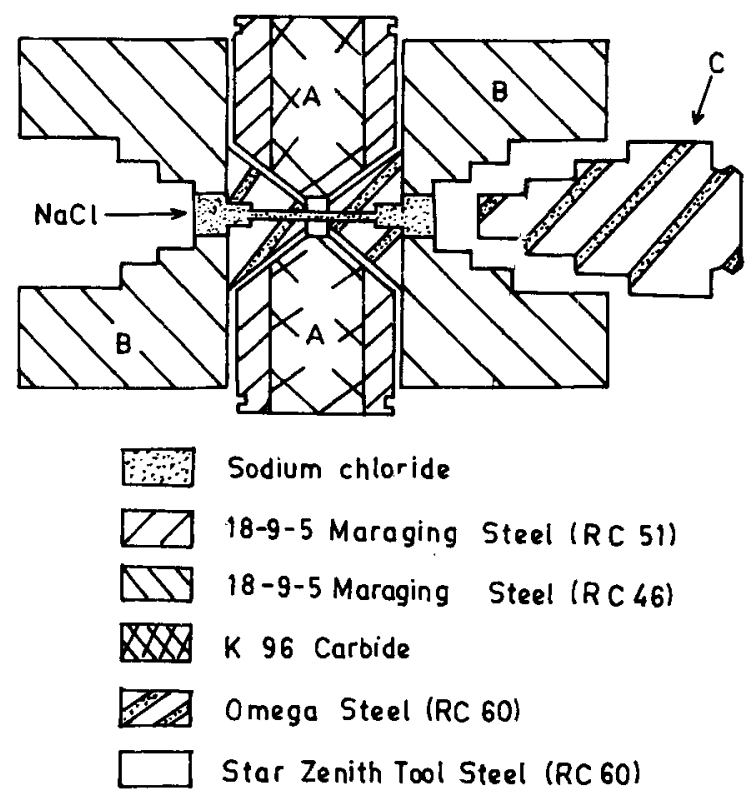

Figure 1. Schematic diagram of the high pressure cell.

phosphorescence accessory using quartz cell. Photoluminescence was excited with the UV lines of an Ar ion laser passed through spex $3 / 4$ meter monochromater and recorded by using RCA C31034 photomultiplier and photon counting equipment coupled with $x-y$ recorder. All spectra are uncorrected for instrument response.

2.2b High pressure photoluminescence spectroscopy: The samples of tetracyanoplatinate encapsulated gel glass were used to record the high pressure photoluminescence spectra using a cell similar to that suggested by Drickamer type I high pressure optical cell (Nicol et al 1972). The cell has three sodium chloride windows, two of which are shown in figure 1. The third window lies in a direction perpendicular to the plane of paper. Each window, which has an outer diameter of $6.3 \mathrm{~mm}$ slowly reduce to around $1 \mathrm{~mm}$ for the inner diameter. The sample was packed into the cylindrical chamber within the cell as far as a thin tungsten piston was placed adjacent to the large crystal $A$ and followed by a $3 \mathrm{~mm}$ diameter disc of $\mathrm{NaCl}$. These two layers elevated the sample so that its placement was in front of windows. A sample, which is a highly transparent glass, along with several ruby chips were placed in the high pressure cell. This is necessary because the sample has a tendency to absorb and emit at their surface by proper displacement of the cell using trial and error method, helps in proper alignment of the luminescence emission with the exit window. Liquid paraffin was used as the high pressure medium in the pressure cell. The sample was then closed off by the large piston A. The sample was excited with Ar ion laser using three different wave lengths $351 \cdot 1$, 488 and $514 \mathrm{~nm}$. Emission from the sample was focussed by lense and monitored at right angle to the excitation. The excitation light was directed perpendicular to a phase of the single crystal and polarized parallel to the crystallographic $C$ axis $(E \| C)$. The pressure was calibrated using the pressure induced shift of the $R_{1}$ ruby line (Noack and Holzapfel 1979) relative to the 6965 A line of an argon lamp. After each increase in 


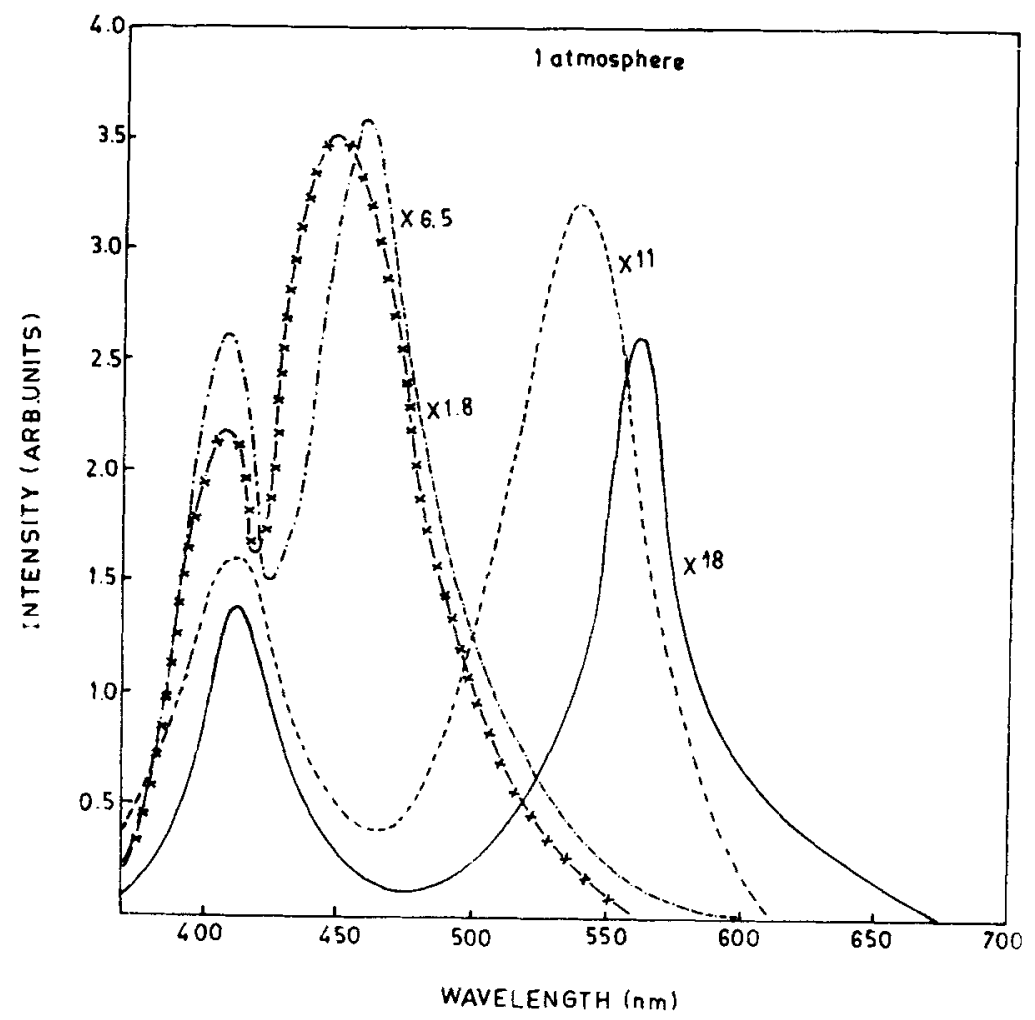

Figure 2. Photoluminescence spectra of $\mathrm{KNaCP}(-), \mathrm{KLiCP}(-\cdots), \mathrm{Cs}_{2} \mathrm{Ca}(\mathrm{CP})(-\cdots)$ and $\mathrm{Cs}_{2} \mathrm{CP}(-\times-)$ one year aged doped gel glasses at $l$ atmospheric pressure $\left(\dot{ }_{\mathrm{e} x}=351 \cdot 1 \mathrm{~nm}\right)$.

pressure, it was necessary for the pressure to equilibrate throughout the system. At each stage emission signal passed through a chopper which was coupled to a lock in amplifier. The emission then entered the monochromater to be scanned over the peak maxima which was then detected by a RCA C 31034 photomultiplier tube and was recorded on a strip chart recorder.

\section{Results}

\subsection{Photoluminescence at atmospheric pressure of sol-gel glasses}

Photoluminescence studies of the tetracyanoplatinate salts KLiCP, KNaCP, $\mathrm{Cs}_{2} \mathrm{Ca}(\mathrm{CP})_{2}$ and $\mathrm{Cs}_{2} \mathrm{CP}$ encapsulated sol-gel glass were recorded using Ar-ion laser with $351 \cdot 1$ and $488 \mathrm{~nm}$ line and the spectra are shown in figure 2 . These atmospheric pressure photoluminescence were obtained under identical geometric and optical conditions. The energies of the peak maxima and full width at half height of the PL emission are compared in table 1 .

The photoluminescence intensities of the sample studied decreases in the order $\mathrm{KNaCP} \rightarrow \mathrm{KLiCP} \rightarrow \mathrm{Cs}_{2} \mathrm{Ca}(\mathrm{CP})_{2} \rightarrow \mathrm{Cs}_{2} \mathrm{CP}$. The photoluminescence spectra are the average spectra of atleast twenty individual measurements and the experimental uncertainties of the PL band maxima are $\pm 6 \mathrm{~nm}$. In the case of $\mathrm{Cs}_{2} \mathrm{CP}$ the photoluminescence 
Table 1. Energies of the peak maxima and the widths at half height for TCP encapsulated sol-gel glasses $(\lambda$ excitation $=$ $351 \cdot 1 \mathrm{~nm}$, temp $=18^{\circ} \mathrm{K}$ ) at $1 \mathrm{~atm}$.

\begin{tabular}{|c|c|c|}
\hline Name of the sample & $\lambda \max (\mathrm{nm})$ & Half width $(\mathrm{nm})$ \\
\hline $\mathrm{KNa}\left[\mathrm{Pt}(\mathrm{CN})_{4}\right]$ & 562 & 32 \\
\hline $\mathrm{KLiPt}(\mathrm{CN})_{4}$ & 540 & 58 \\
\hline $\mathrm{Cs}_{2} \mathrm{Ca}\left[\mathrm{Pt}(\mathrm{CN})_{4}\right]_{2}$ & $462 \cdot 2$ & 56 \\
\hline $\mathrm{Cs}_{2} \mathrm{Pt}(\mathrm{CN})_{4}$ & 450 & 61 \\
\hline
\end{tabular}

intensity has the weakest signal and therefore during measurement uncertainties of the band maxima and the band width is slightly larger. The position of the band maxima corresponding to the characteristic glass emission is almost the same at $410 \pm 2 \mathrm{~nm}$ within experimental error. The emission band maxima of $\mathrm{Cs}_{2} \mathrm{Ca}(\mathrm{CP})_{2}$ is shifted towards higher wavelength compared to $\mathrm{Cs}_{2} \mathrm{CP}$ by almost $12 \pm 1 \mathrm{~nm}$, however, the full width at half height is slightly higher by a factor of 1.09 in $\mathrm{Cs}_{2} \mathrm{CP}$. Interestingly, the emission band maxima of the photoluminescence spectra shows a large shift (almost equal to $100 \mathrm{~nm}$ ) compared to $\mathrm{Cs}_{2} \mathrm{CP}$ in both $\mathrm{KNaCP}$ and $\mathrm{KLiCP}$. In addition, in the latter cases the band widths at half height of the PL band is quite narrow compared to that of $\mathrm{Cs}_{2} \mathrm{Ca}(\mathrm{CP})_{2}$ and $\mathrm{Cs}_{2} \mathrm{CP}$. A large band width in $\mathrm{Cs}_{2} \mathrm{CP}$ may probably be due to larger experimental uncertainty caused by comparatively weak intensity of the PL band in the sample. All these spectra were obtained from more than 25 scans each with a 1 sec collection time.

We have carried out emission studies with undoped plane TEOS which has peaks at 420 and $470 \mathrm{~nm}$ respectively. When excited with $351 \cdot 1 \mathrm{Ar}$ ion laser, the $420 \mathrm{~nm}$ band is assigned to glass emission and $470 \mathrm{~nm}$ peak may be assigned to the gel emission. An interesting feature has been observed with respect to concentration dependence of the dopant molecule $\mathrm{KLiCP}$ and $\mathrm{KNaCP}$. The result shows a strong dependence on the concentration of the dopant molecule as it is seen from figures $5-7$. For $1 \times 10^{-2} \mathrm{M}$ concentration, we have observed an intense band at $586 \mathrm{~nm}$. The peak at $586 \mathrm{~nm}$ may be thought of as due to cluster species. For $1 \times 10^{-5} \mathrm{M}$ concentration, however, we observed a peak at $562 \mathrm{~nm}$ which gives a shift of $26 \pm 1.5 \mathrm{~nm}$ with respect to $1 \times 10^{-2} \mathrm{M}$ concentration. The complete disappearance of the peak corresponding to $\mathrm{Pt}(\mathrm{CN})_{4}^{-2}$ for lower concentration may be due to the fact that with laser irradiation the polymer chain breaks into dimers and higher order clusters, which results in the complete disappearance of the band corresponding to the polymer chain. We assign here the peak at $562 \mathrm{~nm}$ to the dimer and peak corresponding to $586 \mathrm{~nm}$ to the cluster. The relative intensities indicate that the presence of clusters are highly significant in this case. A drastic variation in the characteristics of the luminescence spectra with a change in the concentration of $\mathrm{Pt}(\mathrm{CN})_{4}^{-2}$ ion seems to be due to different species present in the solution having different concentrations which in turn; suggests that the luminescence spectra in fact correspond to different species rather than one species.

\subsection{High pressure photoluminescence spectra}

The pressure dependence of the photoluminescence band of TCP encapsulated gel glass has been observed between atmospheric pressure and $20 \mathrm{kbar}$. All the four 

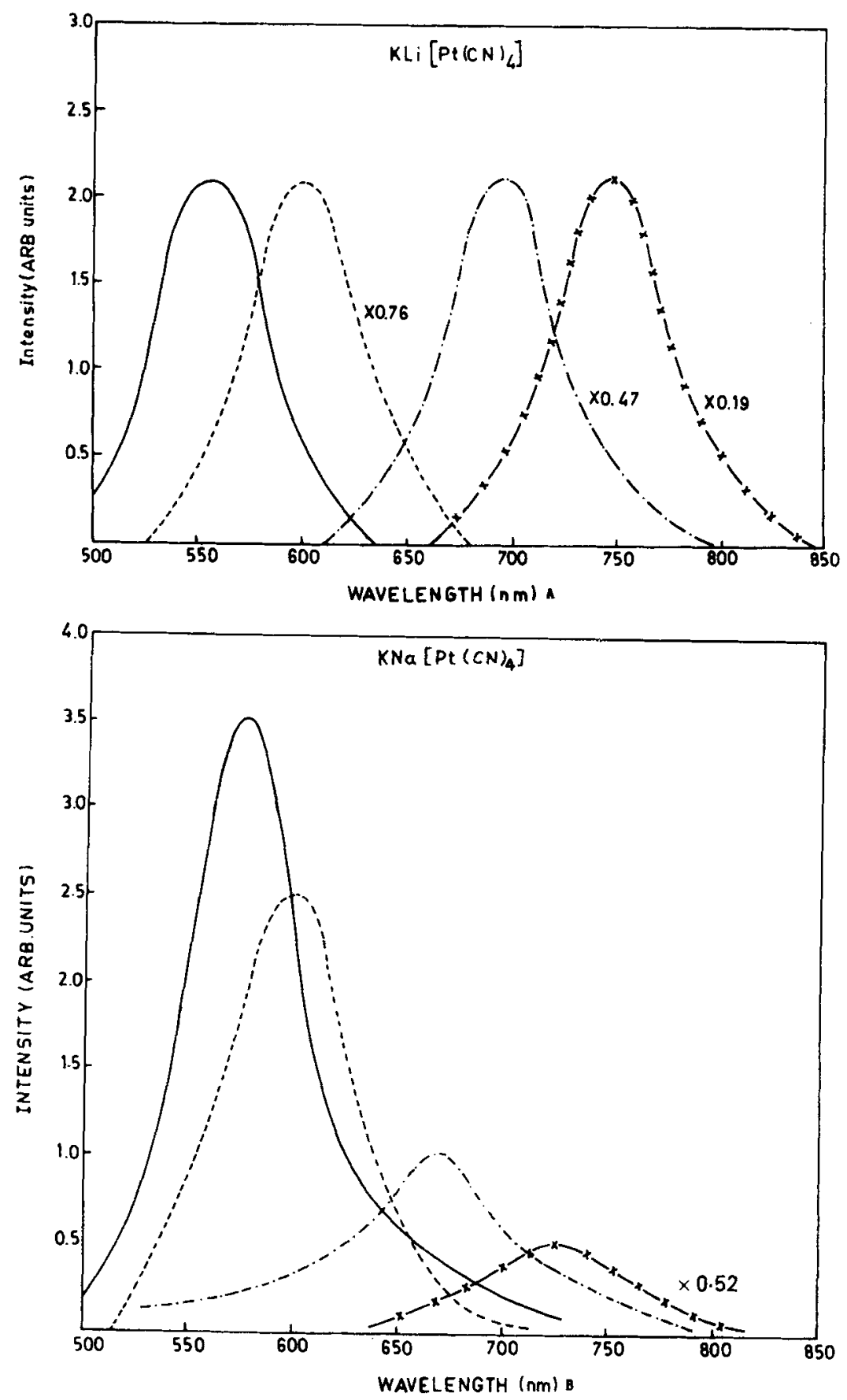

Figure 3. (A) Polarized photoluminescence spectra of KLiCP doped gel glass at four different pressures for $E \| C .\left(\hat{\lambda}_{\text {ex }}=488 \mathrm{~nm}\right)[1 \mathrm{kbar}(--), 8 \mathrm{kbar}(\cdots--), 16 \mathrm{kbar}(-\cdots-), 20 \mathrm{kbar}$ $(-x-x-)]$ and (B) polarized photoluminescence spectra of $\mathrm{KNaCP}$ doped gel glass at four different pressures for $E \| C$. $\left[\lambda_{\mathrm{ex}}=488 \mathrm{~nm}\right][1 \mathrm{kbar}(-), 8 \mathrm{kbar}(\cdots-), 16 \mathrm{kbar}(-\cdots-) .20 \mathrm{kbar}$ $(-x-x)]$. 


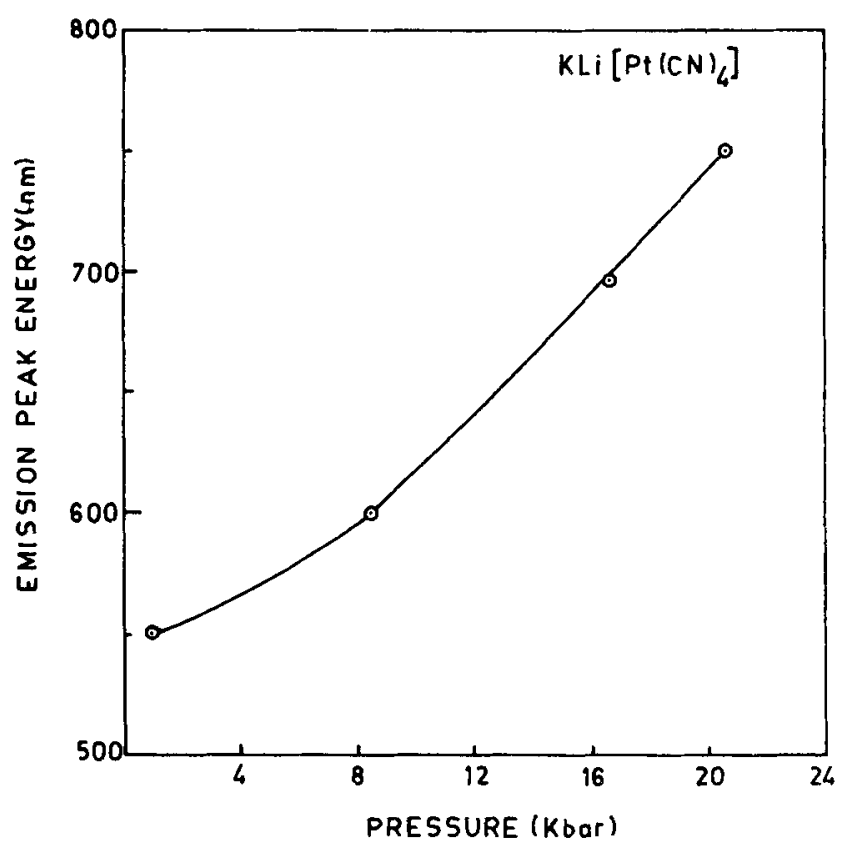

Figure 4. Emission peak energy of KLiCP encapsulated gel glass as a function of pressure.

samples have shown a relatively large shift of the emission maxima towards lower energies with increasing pressure (table 2). The polarization of the pressure dependence spectra is also recorded with few samples. The polarized spectra of KLiCP at four different pressures for $\mathrm{E} \| \mathrm{C}$ have been shown in figure $3 \mathrm{~A}$. The associated spectra corresponding to $\mathrm{E} \perp \mathrm{C}$ has also been recorded. However, when we increase the pressure up to $4 \mathrm{kbar}$ the intensity decreases to a value which could not be recorded within the possible available resolution of the instrument. The polarized PL spectra were taken with $488 \mathrm{~nm}$ laser excitation and had a very well defined sharp peak. The intensity of the polarized emission decreased by a factor of five when pressure increased from $1 \mathrm{kbar}$ to $20 \mathrm{kbar}$. At pressure of greater than $20 \mathrm{kbar}$ the intensity of the $\mathrm{E} \| \mathrm{C}$ polarized band was too weak to be measured. In the case of $\mathrm{KNaCP}$ the polarized PL spectra had emission intensity much higher as compared to previous case and was measured along $\mathrm{E} \| \mathrm{C}$ axis. The emission intensity decreased by a factor of 13 when pressure increased from $1 \mathrm{kbar}$ to $20 \mathrm{kbar}$ (figure $6 \mathrm{~B}$ ). In both the samples, however, at pressures greater than $8 \mathrm{kbar}$, the position of the two bands in both polarization directions were almost identical. Figure 4 showed the emission peak energy of KLiCP encapsulated gel glass as a function of pressure. A sharp dec! ease in the energy of maxima of the band corresponding to $E \| C$ polarization direction starts at nearly $8 \mathrm{kbar}$ and remains upto $20 \mathrm{kbar}$, however, we speculate that a much slower decrease could be observed if pressure extended from $20 \mathrm{kbar}$ onwards.

The slopes of the plot of energy vs pressure was $13 \mathrm{~nm} / \mathrm{kbar}$ for $\mathrm{E} \| \mathrm{C}$ band. Similar high pressure data were plotted for other three sol-gel glasses. In all of these cases the slopes were actually determined between $11 \mathrm{kbar}$ and $18 \mathrm{kbar}$. For $\mathrm{KNaCP}$ between $\sim 1 \mathrm{kbar}$ and $8 \mathrm{kbar}$ increase in the pressure did not shift much the emission peak energy (only $\sim 24 \mathrm{~nm}$ ) well within the limits of the experimental error. This result 


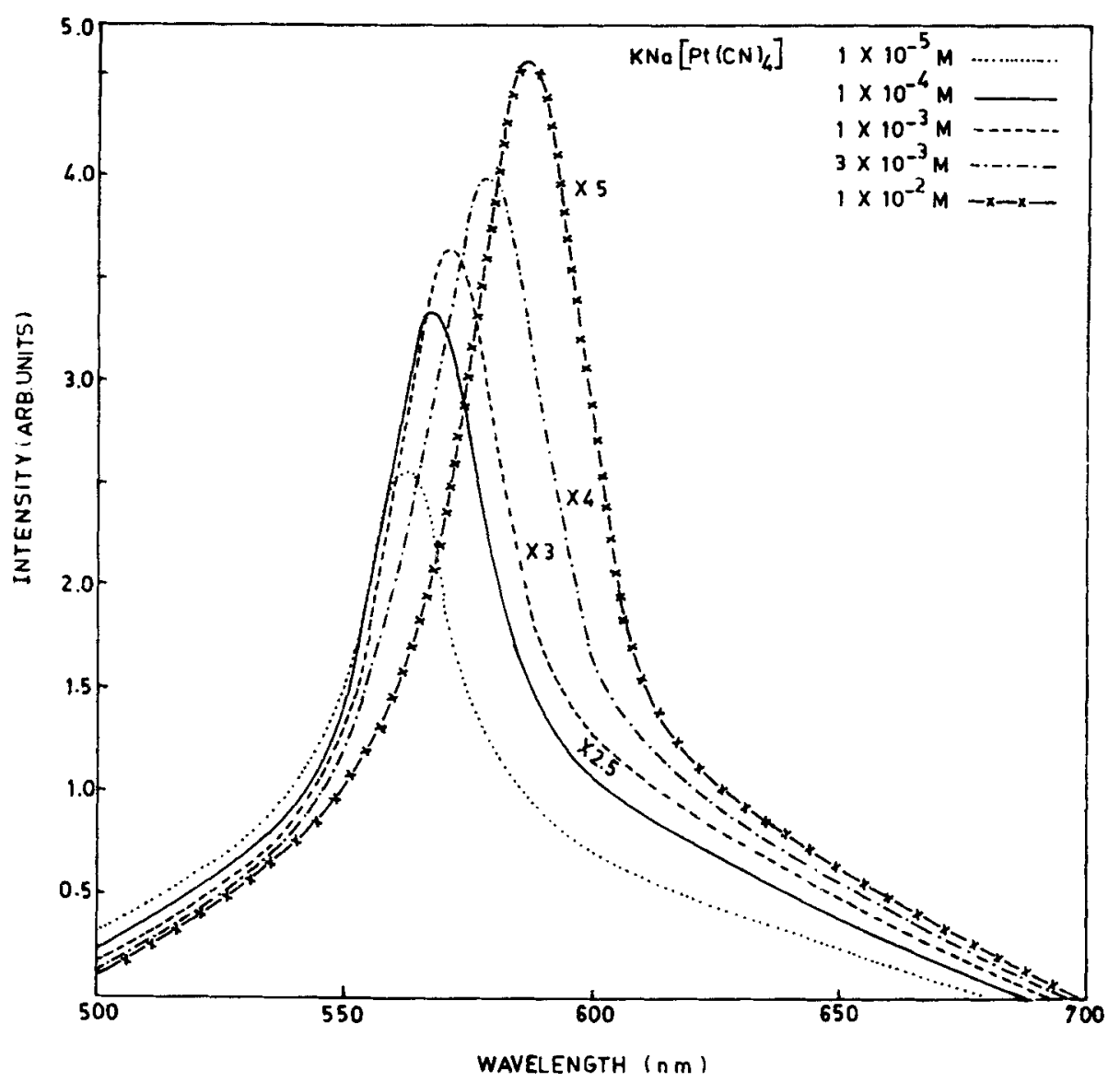

Figure 5. Photoluminescence spectra of 1 year aged samples of gel glasses doped with $\mathrm{KNaCP}$ at different concentrations.

is in contradiction with the earlier result reported by Yersin and Gliemann (1978), according to whom this region was actually in between 11 and $15 \mathrm{kbar}$. This suggests that phase transformation occurs in this region with no or only small changes of the $\mathrm{Pt}-\mathrm{Pt}$ distances. In the case of KLiCP our result suggests that with increasing pressure there is sufficient amount of shift of the emission peak energy which in turn suggests that phase transformation might occur in the gel glass with appreciable change in $\mathrm{Pt}-\mathrm{Pt}$ distances. Another interesting result which we have observed is the concentration dependence of the dopant molecule with respect to emission peak energy.

\section{Discussion}

The emission properties of the four complexes which we have investigated in the present study are in fact actually determined by $\operatorname{Pt}(\mathrm{CN})_{4}^{-2}$ ions. The energy level diagram as discussed by Hidvegi et al (1982) is shown in figure 8. A b-axis half cell 


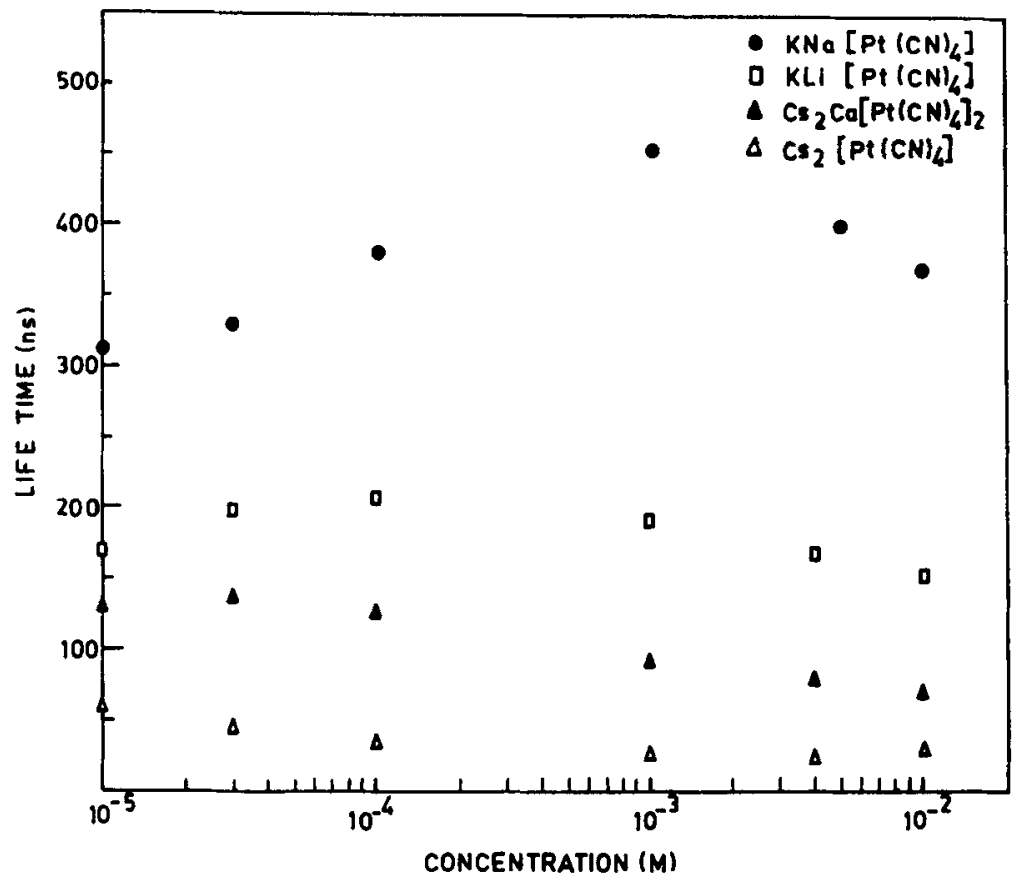

Figure 6. Life time measurement of $\mathrm{KNaCP}, \mathrm{KLiCP}, \mathrm{Cs}_{2} \mathrm{Ca}(\mathrm{CP})_{2}$ and $\mathrm{Cs}_{2} \mathrm{CP}$ encapsulated gel glasses as a function of concentration.

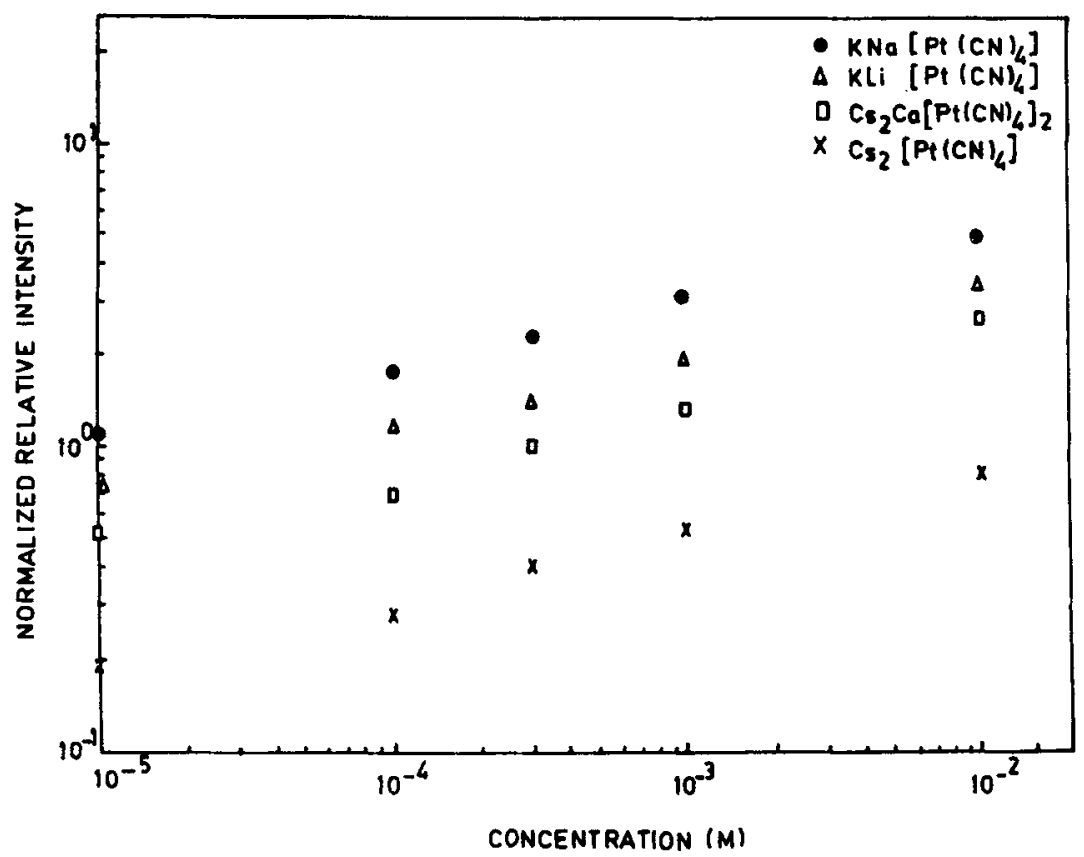

Figure 7. Normalized relative intensity as a function of concentration for different samples of MCP encapsulated gel glasses. 
Table 2. Shift of the emission maxima as a function of pressure for TCP encapsulated sol-gel glasses for $1 \times 10^{-3} \mathrm{M}$ concentration.

\begin{tabular}{lccc}
\hline $\begin{array}{l}\text { Name of the } \\
\text { sample }\end{array}$ & $\begin{array}{c}\text { Emission max at } 1 \\
\text { atm } \lambda \max (\mathrm{nm})\end{array}$ & $\begin{array}{c}\text { Emission max at 20 } \\
\text { kbar } \lambda \max (\mathrm{nm})\end{array}$ & $\begin{array}{c}\text { Shift of the emission max } \\
\text { with respect to 20 kbar nm }\end{array}$ \\
\hline $\mathrm{KLi}\left[\mathrm{Pt}(\mathrm{CN})_{4}\right]$ & 540 & 748 & 208 \\
$\mathrm{KNa}\left[\mathrm{Pt}(\mathrm{CN})_{4}\right]$ & 562 & 724 & 162 \\
\hline
\end{tabular}

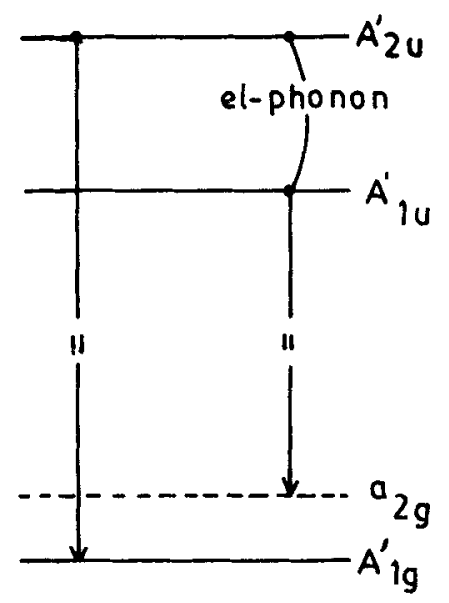

Figure 8. Energy level diagram for the emitting states of a $\left[\mathrm{Pt}(\mathrm{CN})_{4}\right]^{-2}$ chain.

projection of the structure of $\mathrm{KNaCP} \cdot 3 \mathrm{H}_{2} \mathrm{O}$ is shown in figure 9 which falls into $\mathrm{Cc}$ space group. An important finding relevant to the structure property phenomena in these salts is that the crystal structures of the anion deficient materials may be classified into one of the two categories. The hydrated compounds crystallize in the noncentrosymmetric primitive tetragonal space group $\mathrm{P} 4 \mathrm{~mm}$ which contains cations between the $\mathrm{Pt}(\mathrm{CN})_{4}$ groups in the 'upper half' of the unit cell while the water molecules reside in the 'lower half' as shown in figure 9(Williams et al 1974; Peters and Eager 1976; Heger et al 1978). This structure suggests that the Pt-Pt interchain distance can be alternatively compressed or expanded during the course of sol to gel and gel to glass formation and depending upon whether the system is completely dried or may be visualized when the system is irradiated with laser. The compression or expansion in the $\mathbf{P t}-\mathbf{P t}$ intrachain distance may also be due to asymmetric packing of cations and water molecules in the unit cell (Johnson et al 1978).

The emission properties may be understood by the fact that the ground state in $D_{4 \mathrm{~h}}$ symmetry including spin orbit coupling is $A_{1 \mathrm{~g}}^{\prime}$ arising from the ${ }^{1} A_{1 \mathrm{~g}}$ state from the $\left(d_{z}^{2}\right)^{2}(d x z, d y x)^{4}(d x y)^{2}$ electron configuration. The first excited state is ${ }^{3} A_{2 \mathrm{u}}$ according to the electron transition $5 d_{\mathrm{z} 2} \rightarrow 6 p_{\mathrm{z}}, \pi^{*}(\mathrm{CN})$. The ${ }^{3} A_{2 \mathrm{u}}$ splits into a $E_{\mathrm{u}}^{\prime}$ and a $A_{1 u}^{\prime}$ when spin-orbit coupling is taken into account. Transition between the ground state and the excited states $A_{2 \mathrm{u}}^{\prime}$ and $E_{\mathrm{u}}^{\prime}$ are electric dipole allowed with polarization $\mathrm{E} \| \mathrm{C}$ and $\mathrm{E} \perp \mathrm{C}$, respectively. The transition between $A_{\mathrm{lg}}^{\prime}$ and the lowest excited state $A_{1 \mathrm{u}}^{\prime}$ is symmetry forbidden. In thermal equilibrium, as proposed by Leyrer et al (1985), 


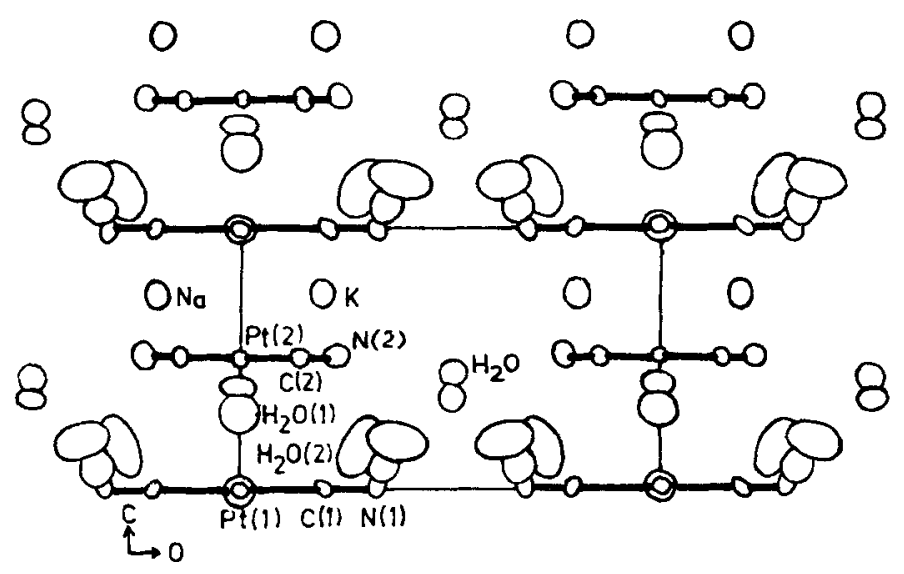

Figure 9. A b-axis half cell projection of the $\mathrm{KNa}\left[\mathrm{Pt}(\mathrm{CN})_{4}\right] \cdot 3 \mathrm{H}_{2} \mathrm{O}$.

at room temperature practically the whole emission intensity is due to the transitions $A_{1 \mathrm{~g}}^{\prime} \leftarrow A_{2 \mathrm{u}}^{\prime}(\mathrm{E} \| \mathrm{C})$ and $A_{1 \mathrm{~g}}^{\prime} \leftarrow E_{\mathrm{u}}^{\prime}(\mathrm{E} \perp \mathrm{C})$.

As a matter of fact the main question is to establish whether the tetracyanoplatinate molecules are indeed incorporated within the bulk of the glass or adsorbed at the exposed walls of the pores. For comparison purpose we have carried out a simple experiment to distinguish between these two facts. First of all a purely undoped TEOS gel glass has been prepared and TCP compound then adsorbed on its surface as previously described by Reisfeld (1983). A doped gel glass and an adsorbed glass were then both immersed into two leaching solvents, water and ethanol. Equilibrium between adsorbed and solvent TCP was reached in the case of the adsorbed glass and solvent became yellowish (quickly for ethanol and slowly for water). We could not observe any detectable leakage of $\mathrm{KNaCP}$ either by eye or by instrument from the doped glass. This fact clearly demonstrates following interesting features about our samples encapsulated with TCP molecules: (i) The MCP is completely trapped in a surrounding rigid cage or (ii) MCP molecules are completely trapped in bottle neck pores as suggested by Unger (1979), with rigid pore entrances of diameter smaller than the effective diameter of ethanol or water (nearly $4 \AA$ ) (McClellan and Harnsberger 1967).

The interesting feature in our samples which are doped with MCP molecule is that they do not show any significant reason for the presence of aggregates. However such aggregations have already been pointed out with laser dye, which have tremendous impact on those processes which are related with lasing properties (Chin et al 1972; Selwin and Steinfeld 1972; Chibisov and Slarnova 1978). This suggests intrinsic dependence on the nature of the local environment of the MCP molecule. However, at this stage of our preliminary report we do not want to question about aggregate fluorescence, when controversy still exists on the role of water, which may cause aggregation (Drexhage 1977).

During polymerization of gel glass, we have observed two types of silicon groups, probably from the walls of the silica glass cage, silanol $(\mathrm{Si}-\mathrm{OH})$ and siloxane $(\mathrm{Si}-\mathrm{O}-\mathrm{Si})$. We know that both these two groups are having lower polarity and higher hydrophobicity than water. As a matter of fact when the more effective $\mathrm{Si}-\mathrm{O}-\mathrm{Si}-\mathrm{O}$ group are linked together with the structure of $\mathrm{KNaCP}$ we believe that the local environment 
around the MCP molecule has an effective siloxane surface with much less hydrophobicity which in turn, improves the probability of non-aggregation. Further, for MCP attached to siloxane planes, has an effective polarity which may resemble the lower chain alkanols. On comparison, we may regard the cage as hydroxylic and relatively polar environment less polar than water.

At this point, it is worthwhile to discuss the configurational aspect of the MCP molecule in the gel glass. We speculate that if the interatomic distances of the $\operatorname{Pt}(\mathrm{CN})_{4}^{-2}$ complexes is almost identical to $\mathrm{Si-} \mathrm{O}-\mathrm{Si}$ separation in the glass one could easily establish the fact that $\mathrm{Pt}(\mathrm{CN})_{4}^{-2}$ complex fits almost identical in the glass. However, we did not perform any $\mathrm{X}$-ray measurement to support our speculation.

The luminescence spectrum of $\mathrm{KNaCP}$ doped sol-gel glass, excited with laser irradiation shows that the assignment corresponding to the peak $562 \mathrm{~nm}$ is actually due to dimer species. However, the peak at $586 \mathrm{~nm}$ may be assigned to cluster of $\operatorname{Pt}(\mathrm{CN})_{4}^{-2}$ ions. The luminescence spectra corresponding to peak at $562 \mathrm{~nm}$ increases with increasing temperatures which in turn may be related to energy transfer mechanism from the dimer to the cluster via non-radiative process. The energy transfer mechanism is more dominant at higher temperatures, however this energy transfer mechanism gets frozen at temperatures below $77 \mathrm{~K}$. To verify this, we carried out time resolved experiment with different decay times at different temperatures to study the relative intensity distribution of the two peaks, the results of which will be discussed elsewhere (Majumdar and Mahajan 1996c).

Figure 6 shows the fluorescence life time of the emission of KNaCP, KLiCP, $\mathrm{Cs}_{2} \mathrm{Ca}(\mathrm{CP})_{2}$ and $\mathrm{Cs}_{2} \mathrm{CP}$. It is seen that the life time changes only little with increasing concentrations. The life time of $\mathrm{Cs}_{2} \mathrm{CP}$ is nearly 6 times less compared to that of $\mathrm{KNaCP}$ at concentration of $10^{-5} \mathrm{M}$. However, it is seen from figure 6 that for $\mathrm{KNaCP}$ life time exhibits an overall increase and attains highest value for $1 \times 10^{-3} \mathrm{M}$ concentration.

Figure 7 shows the integrated emission intensity as a function of four tetracyanoplatinate (II) $\mathrm{M}_{x}\left[\mathrm{Pt}(\mathrm{CN})_{4}\right] n \mathrm{H}_{2} \mathrm{O}(\mathrm{MCP})$ with $\mathrm{M}_{x}=\mathrm{KLi}, \mathrm{KNa}, \mathrm{Cs}_{2} \mathrm{Ca}$ and $\mathrm{Cs}_{2}$ doped sol-gel glasses. This shows that total integrated intensity quantitatively increases with concentration in all four glass samples which in turn, conforms to the qualitative observation that sample radius increases as a function of concentration for all the four MCP doped sol-gel glasses.

Recently Matthews et al (1994) have shown that in europium(III) thenoyltrifluoroacetonate doped silicate gels, the life time increases with increasing concentration, which in turn shows increase in quantum efficiency. They proposed that observed onset of double exponential decay behaviour may probably be associated with cross relaxation or dimerization effects. This result in fact supports our previous concept as laid down in earlier para. The process of dimerization has a key role in TCP doped sol-gel glasses as far as the life time measurements are concerned.

These pressure sensitive probe molecules have revealed us that local pressure of the order of $20 \mathrm{MPa}$ can be calculated by noting down the shift in the luminescence band starting from initial sol to gel and gel to glass transformation. The details of such measurements will be discussed elsewhere (Majumdar and Mahajan 1996a).

In order to arrive at more conclusive picture to characterize the present sol-gel glass system we require further studies like small angle neutron scattering and FTIR spectroscopy. These experiments are in progress and the results of these experiments will be presented elsewhere (Majumdar and Mahajan 1996d). 


\section{Conclusions}

In summary, strong dopant concentration dependences have been found, which yield widely varying luminescence in different TCP doped silicate glass. The time resolved luminescence study in $\mathrm{KNaCP}$ has clearly shown two distinct bands with differing life times which is speculated due to dimer formation. This pressure sensitive probe molecule has also enabled us to calculate drying stresses at different stages of sol to gel and gel to glass system which in turn would be useful in characterizing the system with respect to dopant-matrix and dopant-dopant interaction, so as to enable for the potential development of such systems in the so called photonic media.

\section{Acknowledgements}

One of the authors $(\mathrm{BM})$ is grateful to the Ministry of Human Resource Development, Department of Education, New Delhi for awarding Post Doctoral Fellowship at UCLA, Los Angeles (U.S.A.) and to Prof. J I Zink for providing experimental facility. Authors also thank Prof. B P Ambastha and Prof. D P Saha, Government College of Science, Raipur for their constant support and encouragement. Authors also thank MAPCOST for providing research grant for the current project.

\section{References}

Chibisov A K and Slarnova T D 1978 J. Photochem. 8285

Chin S L, Leclerc N and Bedarad G 1972 Opt. Commun. 6264

Drexhage K H 1977 Dye lasers (ed.) F P Schafer (Berlin: Springer) 2nd ed. Chapter 4

Esquivias L and Zarzycki J 1988 Ultrastructure processing of advanced ceramic (eds) J D Mackenzie and D R Ultrich (New York: Wiley) p. 255

Gesser H D and Goswami P C 1989 Chem. Rev. 89765

Heger G, Deiseroth H J and Schuitz H 1978 Acta Crystallogr. B34 725

Hidvegi I, von Ammon W and Gliemann G 1982 J. Chem. Phys. 764361

Holzapfel W $1978 \mathrm{PhD}$ thesis, University of Regensburg, Regensburg

Holzapfel W, Yersin H and Gliemann G 1981 Z. Krist. 15747

Johnson P L, Schultz A J, Underhill A E, Watkins D M, Wood D J and Williams J M 1978 Inorg. Chem. 17839

Knobbe E T, Dunn B and Zink J I 1989 Proc. 4th inter. conf. on ultrastructure processing, Tucson (New York: Wiley)

Krogmann K 1969 Angew. Chem. 8110

Kundu D, Biswas P K and Ganguly D 1989 J. Noncryst. Solids 11013

Leyrer E, Zimmermann F, Zink J I and Gliemann G 1985 Inorg. Chem. 24102

Maffly R L, Johnson P L and Williams J M 1977 Acta Crystallogr. B33 884

Majumdar B and Mahajan M 1996a Proc. of sixth int. conf. on platinum group metals (Dalton: Royal Society of Chemistry) p. 19

Majumdar B and Mahajan M 1996b Pramana-J. Phys. (in preparation)

Majumdar B and Mahajan M 1996c J. Luminescence (to be communicated)

Majumdar B and Mahajan M 1996d J. Noncryst. Solids (in preparation)

Matthews L R, Wang X and Knobbe E T 1994 J. Noncryst. Solids 17844

McClellan A I and Harnsberger H F 1967 J. Colloid Interface Sci. 25577

Moreau-Colin M L 1972 Struct. Bonding 10167

Mukharjee S P 1980 J. Noncryst. Solids 42477

Noack R A and Holzapfel W B 1979 High pressure science and technology (New York: Plenum Press) vol. 1

Nicol M, Ebisuzake Y, Ellesson W D and Karim A 1972 Rev. Sci. Instrum. 43368

Peters C and Eager C F 1976 Inorg. Chem. 15782 
Prasad P N 1989 Proc. 4th int. conf. on ultrastructure processing. Tucson. Arizona (New York: Wiley)

Reisfeld R 1983 J. Less Common Metals 93243

Ro Jae Chul and Chung I J 1989 J. Noncryst. Solids 11026

Roy R 1987 Science 2381664

Scherer G W 1986 J. Noncryst. Solids 87199

Scherer G W 1987a J. Noncryst. Solids 89217

Scherer G W 1987b J. Noncryst. Solids 92122

Scherer G W 1988 J. Noncryst. Solids 99324

Scherer G W 1989 J. Noncryst. Solids 107135

Scherer G W $1990 \mathrm{~J}$. Am. Cerum. Soc. 733

Schultz A J, Williams J M and Brown R K 1982 Advances in organometallic and inorganic polymer science (eds) C E Carraher et al (New York: Marcel-Dekker Inc.) p. 313

Selwin J E and Steinfeld J I 1972 J. Phys. Chem. 76762

Stock M and Yersin H 1976 Chem. Phys. Lett. 40423

Unger K 1979 Porous silica (Amsterdam: Elsevier)

Viswanath A K, Krogh-Jespersen M B. Vetuskey J, Baker C, Ellenson W D and Patterson H H $1981 \mathrm{Mol}$. Phys. 421431

von Ammon W and Gliemann G J 1982 Chem. Phys. 772266

Williams J, Peterson J L, Gerder H M and Peterson S W 1974 Phys. Rev. Lett. 331079

Williams J, Iwata M, Peterson S W, Leslie K A and Guggenhim H J 1975 Phys. Rev. Lett. 341653

Yersin H and Gliemann G 1978 Ann. N. Y. Acad. Sci. 313539

Yersin H, Hidvegi I, Gliemann G and Stock M 1979 Phys. Ret. B. Condense Matter 19177 